\title{
Factors Associated With The Adherence To Unsupervised Daily Dose To Seasonal Malaria Chemoprevention In Builsa North District, Upper East Region Of Ghana
}

Cheick Oumar Doumbia ( $\sim$ doumbiach@outlook.com )

University Clinical Research Center https://orcid.org/0000-0001-5516-0907

\section{Ernest Kenu}

UG School of Public Health: University of Ghana School of Public Health

Ilo Dicko

University Clinical Research Center / USTTB

Mountaga Diallo

University Clinical Research Center/USTTB

\section{Brahima Konate}

University Clinical Research Center/USTTB

\section{Samba Diarra}

University Clinical Research Center/USTTB

\section{Mahamadou Diakite}

University Clinical Research Center/USTTB

\section{Seydou Doumbia}

Clinical Research Center/USTTB

\section{Research}

Keywords: Malaria, Seasonal Malaria Chemoprevention, Children under five, Amodiaquine Sulfadoxine Pyrimethamine, Adherence.

Posted Date: May 10th, 2021

DOI: https://doi.org/10.21203/rs.3.rs-438055/v1

License: (c) (1) This work is licensed under a Creative Commons Attribution 4.0 International License.

Read Full License 


\title{
FACTORS ASSOCIATED WITH THE ADHERENCE TO UNSUPERVISED DAILY DOSE TO SEASONAL MALARIA CHEMOPREVENTION IN BUILSA NORTH DISTRICT, UPPER EAST REGION OF GHANA
}

\author{
Authors: Cheick Oumar Doumbia ${ }^{1,2}$, Ernest Kenu ${ }^{2}$, Ilo Dicko ${ }^{1}$, Mountaga Diallo ${ }^{1}$, Brahima Konate $^{1}$, \\ Samba Diarra $^{1}$, Mahamdou Diakite ${ }^{1,3}$, Seydou Doumbia ${ }^{1}$
}

\begin{abstract}
Background: Since 2015, SMC with amodiaquine-sulfadoxine-pyrimethamine (AQ-SP) has been implemented during the high malaria transmission season in three regions of Ghana. Adherence to the Seasonal Malaria Chemoprevention (SMC) is one of the critical determinants for successfully protecting children under five. In Ghana, SMC In Ghana, the SMC implementation was started in 2015. The purpose of this study was to determine the level of Adherence to SMC and the associated factors among caregivers in Builsa North District.

Methods: We conducted a cross-sectional study in four (4) sub-districts in the Builsa North District. The district was stratified into six, and four subdistricts were selected using simple random sampling. We started recruitment at the community chief's house the researcher randomly selected the direction of movement. The 435 participants were recruited via balloting using a random sampling procedure. The knowledge of caregivers on Malaria and SMC was assessed by scoring correct answers to questions related to malaria and SMC. The association between SMC adherence and independent variables was tested using Pearson's chi-square test and Fisher Exact Test. Simple and multiple logistic regressions were performed to determine associations between SMC adherence and the independent variables, with all results interpreted at $95 \%$ confidence level.

Results: The SMC adherence rates among the caregivers in the Builsa North District was $95.36 \%(416 / 435)$ with an awareness level of $97.94 \%$. The reasons reported for non-adherence were the child's refusal (38.46\%), the child's vomiting of the drug (33.33\%), the occurrence of an illness within the period of medication $(15.38 \%)$, the forgetting to give the subsequent doses (12.82\%). About half $(49.31 \%)$ of caregivers had a good knowledge of malaria, while $66.51 \%$ had a fair knowledge of SMC. Significant predictors of SMC on multiple logistic regression were the place of residence aOR $=3.59,95 \%$ CI [1.02-12.56] caregivers dissatisfied $\mathrm{aOR}=0.10,95 \% \mathrm{CI}[0.01-0.74]$, and being informed by a friend $\mathrm{aOR}=0.04,95 \% \mathrm{CI}[0.00-0.51]$.

Conclusion: This study found a very high adherence rate to SMC in Builsa North District. The key factors associated with SMC Adherence were being aware of SMC through non-health professional source, place of residence, and caregivers' satisfaction with the previous SMC campaign.
\end{abstract}

Keywords: Malaria - Seasonal Malaria Chemoprevention - Children under five - Amodiaquine Sulfadoxine Pyrimethamine - Adherence.

\section{Background}

Intermittent Preventive Treatment in infants is a primary health intervention designed to prevent malaria in children under five years of age during high malaria transmission, which occurs during the rainy season. This intervention is commonly known as Seasonal Malaria Chemoprevention (SMC). During this period, SMC effectiveness has been shown in malaria prevention in children. The implementation of this chemoprevention is done through routine immunization services by admitting a combination of sulfadoxine-pyrimethamine and amodiaquine in children aged 3 to 59 months, regardless of whether the child is infected with malaria. The World Health Organization has recommended this combination since March 2012 for children living in areas of highly seasonal malaria transmission in the Sahel subregion of Africa [1]. In 2014, seven countries in sub-Saharan Africa (Burkina Faso, Chad, Mali, Niger, Nigeria, Gambia, and Guinea) had adopted this malaria control strategy [2]. According to the World Health Organization, 15.7 million children in 12 countries in Africa's Sahel subregion were protected through seasonal malaria chemoprevention (SMC) in 2017. This intervention is effective, cost-effective, safe, and feasible for preventing malaria in children under 5.

In Ghana, the National Malaria Control Program started the implementation in 2015 in the Upper West Region (UWR). Following the implementation of SMC in UWR, an impact assessment showed that SMC's efficacity was $45 \%$. Based on this success, the intervention was extended to the Upper East Region (UER) in 2016.

Most of the studies have analyzed SMC's efficacity, impact, accessibility, availability, and coverage. Few studies examining hidden sociodemographic, operational, individual, and seasonal factors within the household predict, encourage, or prevent the adherence to SMC [3,4]. These challenges in the non-adherence fail to protect the child from malaria infection. This interrupted protocol may induce AQ-SP resistant development, 
which has devastating consequences of malaria burden in children under 5 . The prevalence, the morbidity, and the mortality of malaria in children under 5 would be more likely to be perpetuated if studies are not delved into to fish out such factors or predictors that are associated with the adherence of SMC within caregivers, for appropriate recommendations and amendments, advocacy be tabled to control the situation [4].

According to the National Malaria Control Program (NMCP) reports, the SMC campaign coverage in 2018 was more than $99 \%$, and children under five are still facing infections of malaria and its consequences. It is necessary to understand why some children under the age of five suffer malaria despite having a high SMC implementation coverage. This study investigated using a quantitative method the adherence to the three-dose finalization of SMC among caregivers in Builsa North in Ghana.

\section{Methods}

A cross-sectional household survey was conducted in four (4) subdistricts of Builsa North Districts, Upper East Region of Ghana.

Sampling Strategy: Multi-stage sampling procedure was used. As several sampling methods, it was used at various stages to get multiple sampling units right from the district level to the last smallest sampling unit-the respondents at the different households.

The Builsa North District was stratified into six (6) sub-districts (Sandema Central, Bilinsa- Bilimonsa,Wiaga Central, Chuchuliga Central, Siniensi-Yikpien, Suwarensa-Ndaasa) to ensure fair representation of some of the population's essential characteristics. At this point, simple random sampling by non-replacement balloting was used to select four (4) communities from the six (6) strata by balloting where the names of the different subdistricts or communities were written on pieces of paper, folded, and placed in a bowl.

Eyes closed; a hand was dipped into the bag to choose a folded paper without replacement. The sub-districts selected in this way were used as study sites where caregivers were recruited for the study. A proportionate sampling approach was used to assess the number of participants included per population.

At the community level, each community was stratified into four areas, east, west, south, and north. Starting from the community chief's house, the researcher randomly selected the direction of movement. Depending on the direction chosen, for instance, to the west, the researcher went from house to house in that direction, then to the south, east, and north in the same area.

At the household level, in each house, a caregiver who was 18 years of age or older and accepted to take part in the study and lived in a household and fulfilled all the inclusion criteria was interviewed. In the case that a house had more than one household, one of them was chosen randomly to complete a questionnaire. In the event that the sample size was not obtained from one area due to a lack of eligible participants on the population of each area, data collection proceeded in the next enumeration area. This method was repeated until the final size of the sample was collected.

The number of interviews was performed in each sub-district depended on the approximate proportion of women of reproductive age. We assumed that women around reproductive age (18-49) were the primary caregivers for drug administration during SMC campaigns for this study. In this study, we chose the age groups (1554) as the target population. We used the World Bank demographic database on the distribution of age groups by sex.

Data Collection: This study used closed-ended tructured questionnaire to collect data from the 435 participants from the four (4) sub-districts using a face-to-face interview. The questionnaire was designed in simple English to reflect the study variables and allow easy translation by research assistants (RAs). However, during the interview, the participants were asked to sign the inform consent form anfter the, the questions were asked or translated into local dialects (Buli language, Kantonsi language, Fulani language, Dagomba language, Mossi language, Agari language) for better understanding, especially for participants who did not receive formal education during the administration. The questionnaire questions focused on the respondents' specific vital demographic characteristics, general knowledge about malaria, and general knowledge about SMC. The tool was pre-tested with twenty (20) households in Navrongo (Kassena-Nankana District), which is an adjacent district of Builsa North District in the Upper East Region of Ghana. During the pre-test, all the ambiguities concerning supervision and asking questions were corrected.

Data Management and Data Analysis: The raw data of the field, was manually cross-checked to ensure completeness, and was entered in Kobo-collect using tablets, then downloaded as a Microsoft Excel file before being exported to STATA version 16 (Stata Corporation, College Station, Texas) for further management and analysis. To ensure accuracy and completeness, the data was further cleaned up by running the frequencies of all variables to verify incorrect coding using STATA.

The proportion of caregivers who adhered to SMC reported in proportion by dividing the number of caregivers who said their children completed the three doses of AQ+SP.

Basic descriptive statistics were obtained on the sociodemographic characteristics of the respondents and the knowledge variables.

Two derived variables on the malaria knowledge level and SMC knowledge level were generated in STATA by scoring the knowledge dichotomous knowledge variables. While a correct answer was given, it was scored as 
1 , and a wrong answer was scored as 0 . Then total scores were categorized into four groups: poor knowledge, insufficient knowledge, good knowledge, and very good knowledge.

The results were presented in frequencies and percentages using tables and graphs. Frequencies were generated to describe categorical variables. Continuous variables were expressed as arithmetic means and standard deviations for normally distributed variables, median, and quartiles for variables not following the binominal distribution.

Pearson's chi-square $\left(\chi^{2}\right)$ test was used to compare the proportions in cross tables with high observed observation, and the Fisher exact test was used to compare the proportions with low observed observation. The bivariate analysis (Fisher exact test and Chi-square test) was used to assess the crude association between potential predictors of the adherence, while univariate analysis was performed to estimate the strength of associations between the adherence and its predictors after controlling for the covariates. After then, all the independent variables with p-value from $0 \%$ to $50 \%$ were used to perform different regressions models.

\section{Results}

A summary of the various characteristics of participants is in Table 1.

Table 1: Sociodemographic characteristic of caregivers in the Builsa North District

\begin{tabular}{|c|c|c|}
\hline Sociodemographic Characteristic & Frequency & Percentage \% \\
\hline \multicolumn{3}{|l|}{ Age } \\
\hline Median (minimum-maximum) & $29(18-50)$ & - \\
\hline$<20$ & 18 & 4.36 \\
\hline $20-29$ & 208 & 47.71 \\
\hline $30-39$ & 164 & 37.61 \\
\hline $40-49$ & 45 & 10.32 \\
\hline \multicolumn{3}{|l|}{ Marital Status } \\
\hline Never married & 80 & 18.35 \\
\hline Married & 265 & 60.78 \\
\hline Cohabiting & 60 & 13.76 \\
\hline Divorced & 17 & 3.9 \\
\hline Widowed & 14 & 3.21 \\
\hline \multicolumn{3}{|l|}{ Religion } \\
\hline Christian & 357 & 81.88 \\
\hline Muslim & 55 & 12.61 \\
\hline Traditional & 24 & 5.5 \\
\hline \multicolumn{3}{|l|}{ Ethnic } \\
\hline Builsa & 343 & 78.67 \\
\hline Mossi & 40 & 9.17 \\
\hline Sissala & 28 & 6.42 \\
\hline Others* & 25 & 5.74 \\
\hline \multicolumn{3}{|l|}{ Educational Status } \\
\hline No formal education & 163 & 37.39 \\
\hline Primary & 77 & 17.66 \\
\hline Secondary & 99 & 22.71 \\
\hline Higher & 97 & 22.25 \\
\hline \multicolumn{3}{|l|}{ Occupation } \\
\hline Unemployed/Housewife & 215 & 49.31 \\
\hline Formal work & 122 & 27.98 \\
\hline Others** & 99 & 22.71 \\
\hline \multicolumn{3}{|l|}{ Number of Children under five } \\
\hline One child & 281 & 64.45 \\
\hline Two children and more & 155 & 35.55 \\
\hline
\end{tabular}

Household Size 


$\begin{array}{lll}\text { Mean ( } \pm \text { Standard deviation) } & 5.24( \pm 1.63) & - \\ \text { Median (minimum-maximum) } & 5(3-8) & - \\ 3-4 & 163 & 37.39 \\ 5-6 & 164 & 37.61 \\ 7-8 & 109 & 25.00\end{array}$

*: Fulani, Akan, dago; **: artisan, hairdressing, farming, buying, and selling. 


\section{Adherence level to the SMC first round in 2020}

Most of the caregivers interviewed, 90.87\% (396/435) reported that all their children received the AQ+SP from drug distributors during the first round of 2020. The adherence rate to SMC among caregivers of those whose children were covered during the first-round drug distribution was $95.36 \quad$ (416/435) \% (Fgure1).

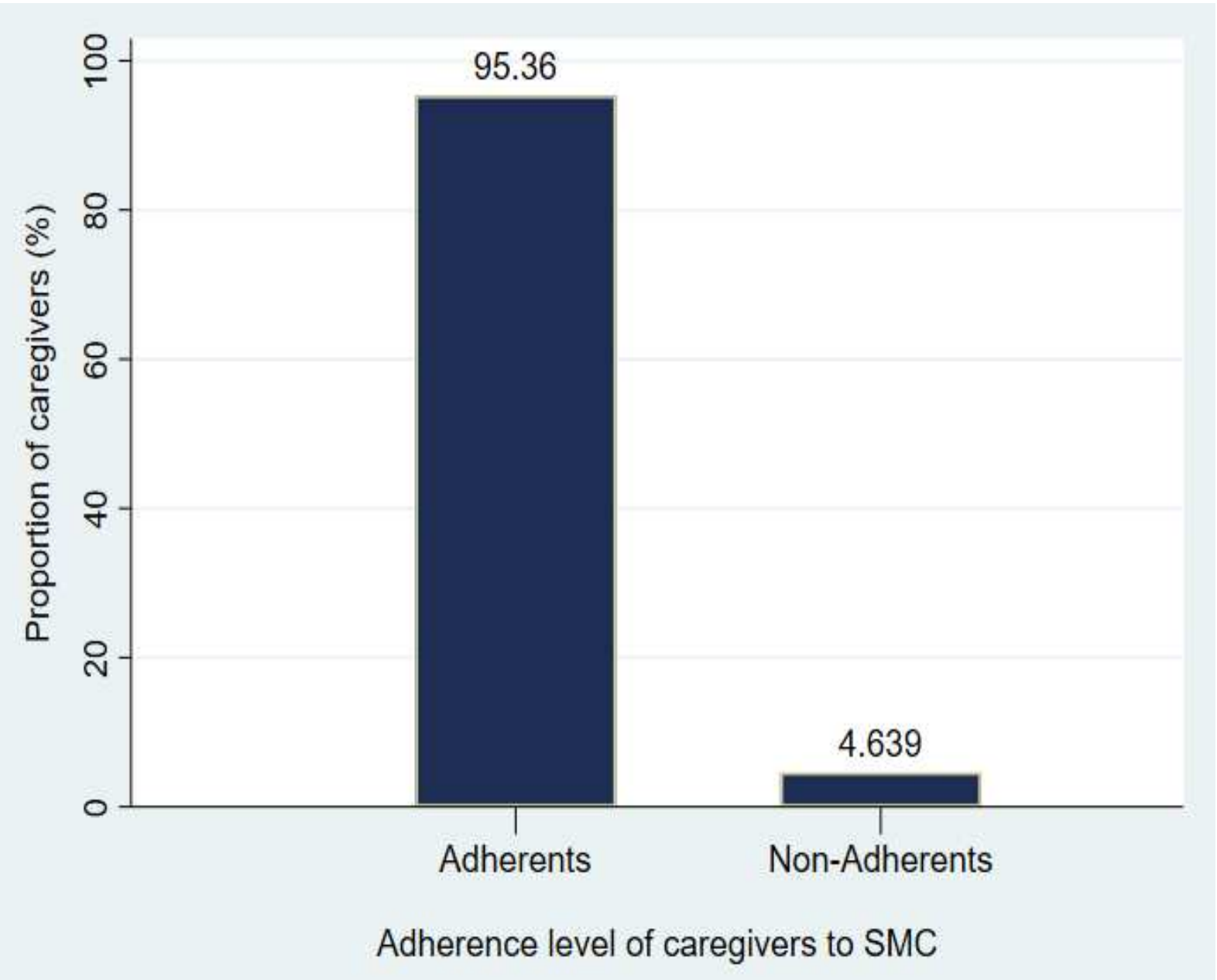

Figure 1: Adherence level of caregivers to SMC during the first in Builsa North District 2020

\section{Reasons for non-adherence}

Four main reasons were reported by the 18 caregivers who did not adhere to SMC during the first round of drug distribution. The primary cause they said for non-adherence was the child's refusal which represented 38.46\% (7/18), followed by the child's vomiting of the drug administration, the occurrence of an illness within the medication period. Besides, $12.82 \%(2 / 18)$ reported that they forgot to give the drugs the subsequent two days. These results are shown in Figure 2 below. 


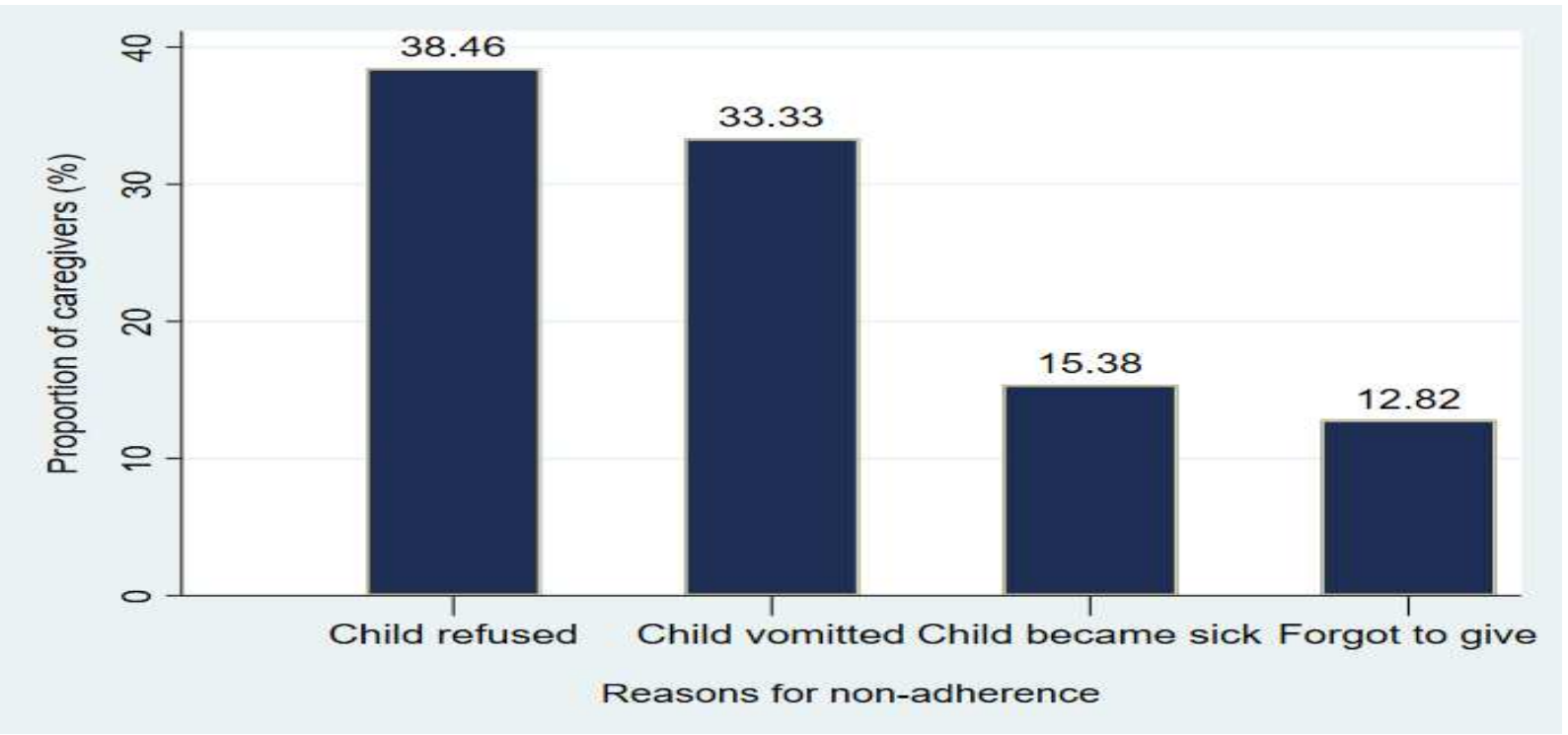

Figure 2: Reasons for non-adherence to unsupervised daily treatment doses of SMC Awareness and Knowledge levels

Almost all the respondents, 97.94\% (427/435), reported having ever heard of SMC, as seen in Figure 3. Among those aware of SMC, the responses were collected from the knowledge assessment on malaria in children and SMC summarized in table 2 .

\section{Proportion of awereness about SMC among caregivers}

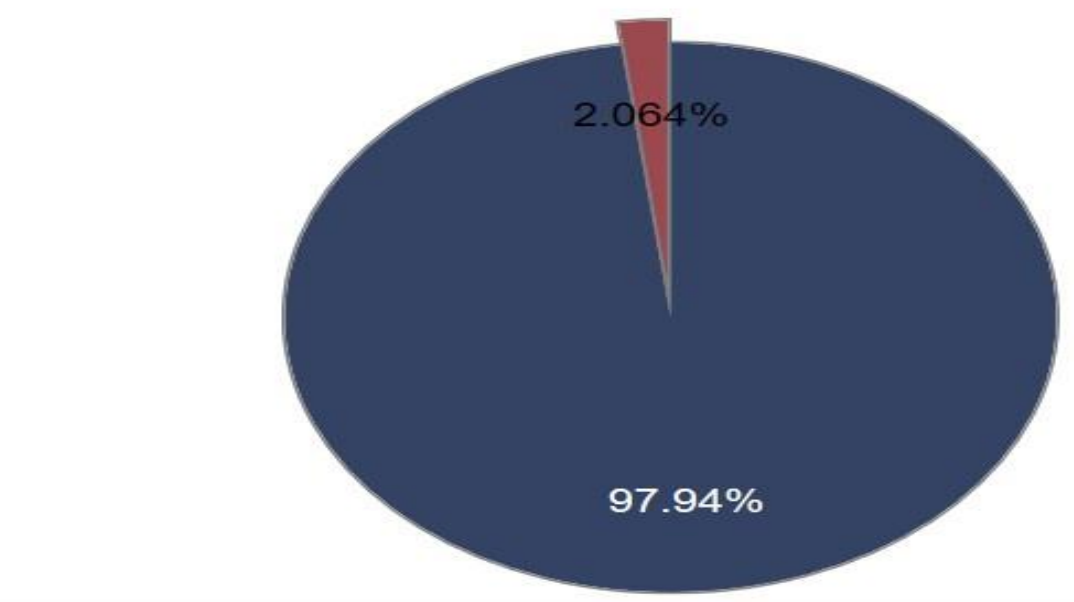

Never heard about SMC

Ever heard about SMC

Figure 3: Levels of awareness of Seasonal Malaria Chemoprevention 
Table 2: Knowledge of Malaria and SMC among caregivers

\begin{tabular}{|c|c|c|}
\hline Knowledge Variables & Responses & F requency (\%) \\
\hline \multicolumn{3}{|l|}{ Malaria } \\
\hline \multicolumn{3}{|l|}{ Cause of malaria } \\
\hline & Mosquito bite & $430(98.62)$ \\
\hline \multicolumn{3}{|l|}{ Effect of untreated malaria on child } \\
\hline & Anemia & $395(90.60)$ \\
\hline & Convulsion & $409(93.81)$ \\
\hline & Mental Confusion & $400(91.74)$ \\
\hline & Death & $401(91.97)$ \\
\hline \multicolumn{3}{|l|}{ Malaria Preventive methods } \\
\hline & Insecticide Treated Nets & $403(92.43)$ \\
\hline & Daily use of mosquito repellent & $405(92.89)$ \\
\hline & IRS during the rainy season & $203(46.67)$ \\
\hline \multicolumn{3}{|l|}{ Seasonal Malaria Chemoprevention } \\
\hline Purpose of SMC & Prevent malaria in children under five & $288(78.69)$ \\
\hline Number of regimens & 3 doses & $242(66.12)$ \\
\hline Intervention season in the year & Only raining season & $255(69.67)$ \\
\hline Number of days for a child & Three days & $295(80.60)$ \\
\hline Minimum age required for SMC medication & Three months & $18(4.92)$ \\
\hline
\end{tabular}

In General, half of the respondents, 49.31\% (215/435), had good knowledge of malaria in children, while 2.29\% (10/435) had poor knowledge. The Knowledge level on SMC was mainly fair for respondents $66.51 \%$ (290/435), while a few had good knowledge of $8.26 \%$ (36/435). Those who had very good knowledge of SMC represented the minority 4.13\% (18/435) Table 3. 
Table 3: Level of Knowledge of caregivers on Malaria and SMC

\begin{tabular}{lll}
\hline & Malaria & SMC \\
\hline Level of Knowledge & Frequency (\%) & Frequency (\%) \\
Poor knowledge & $10(2.29)$ & $92(21.10)$ \\
Fair knowledge & $59(13.53)$ & $290(66.51)$ \\
Good knowledge & $215(49.31)$ & $36(8.26)$ \\
Very good knowledge & $152(34.86)$ & $18(4.13)$ \\
\hline
\end{tabular}

Nearly half of the respondents, $43.56 \%$, reported that local radios are their source of knowledge on SMC, followed by health centers $29.04 \%$ and community health workers $11.71 \%$. However, some minorities reported public announcements, friends, and TV as their source of knowledge on SMC presented in Figure 4.

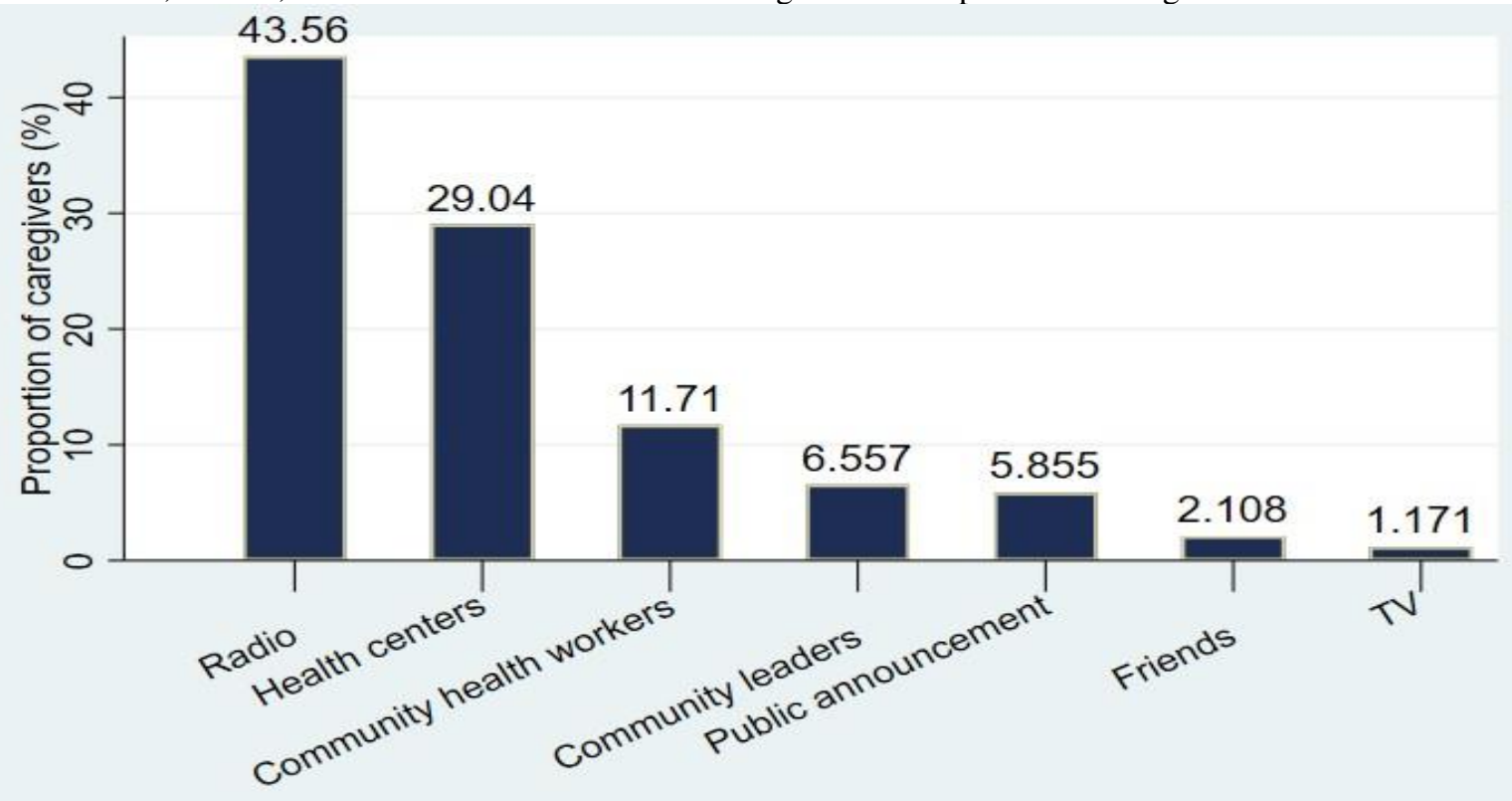

Sources of Knowledge on SMC

Figure 4: Source of Knowledge on SMC 


\section{Sociodemographic and adherence to unsupervised daily treatment doses}

Respondents under the age of $20(5.26 \%)$, Muslims (10.42\%), married $(61.34 \%)$ trained $(35.51 \%)$, single and widowed $(8.33 \%)$, those with primary education $(7.04 \%)$, housewife $(5.38 \%)$, those residing in smaller households $(5.88 \%)$ and those with two or more children were more likely to be non-adherent. However, there was no statistically significant relationship between age, gender, marital status, race, educational degree, profession, household size, number of children under five, SMC knowledge level, Malaria knowledge level, and adherence (p-value?). There was statistical significance for adherence with source of knowledge ( $\mathrm{p}$-value $=0.007)$ and satisfaction level $(\mathrm{p}$-value $=$ 0.000). These results are illustrated below in Table 4.

Table 4: Sociodemographic factors and adherence to unsupervised daily treatment doses of SMC.

\begin{tabular}{|c|c|c|}
\hline Sociodemographic Characteristic & Frequency & Percentage \% \\
\hline \multicolumn{3}{|l|}{ Age } \\
\hline Median (minimum-maximum) & $29(17-50)$ & - \\
\hline$<20$ & 19 & 4.36 \\
\hline $20-29$ & 208 & 47.71 \\
\hline $30-39$ & 164 & 37.61 \\
\hline $40-49$ & 45 & 10.32 \\
\hline \multicolumn{3}{|l|}{ Marital Status } \\
\hline Never married & 80 & 18.35 \\
\hline Married & 265 & 60.78 \\
\hline Cohabiting & 60 & 13.76 \\
\hline Divorced & 17 & 3.9 \\
\hline Widowed & 14 & 3.21 \\
\hline \multicolumn{3}{|l|}{ Religion } \\
\hline Christian & 357 & 81.88 \\
\hline Muslim & 55 & 12.61 \\
\hline Traditional & 24 & 5.5 \\
\hline \multicolumn{3}{|l|}{ Ethnic } \\
\hline Builsa & 343 & 78.67 \\
\hline Mossi & 40 & 9.17 \\
\hline Sissala & 28 & 6.42 \\
\hline Others* & 25 & 5.74 \\
\hline \multicolumn{3}{|l|}{ Educational Status } \\
\hline No formal education & 163 & 37.39 \\
\hline Primary & 77 & 17.66 \\
\hline Secondary & 99 & 22.71 \\
\hline Higher & 97 & 22.25 \\
\hline \multicolumn{3}{|l|}{ Occupation } \\
\hline Unemployed/Housewife & 215 & 49.31 \\
\hline Formal work & 122 & 27.98 \\
\hline Others** & 99 & 22.71 \\
\hline \multicolumn{3}{|l|}{ Number of Children under five } \\
\hline One child & 281 & 64.45 \\
\hline Two children and more & 155 & 35.55 \\
\hline \multicolumn{3}{|l|}{ Household Size } \\
\hline Mean ( \pm Standard deviation) & $5.24( \pm 1.63)$ & - \\
\hline Median (minimum-maximum) & $5(3-8)$ & - \\
\hline $3-4$ & 163 & 37.39 \\
\hline
\end{tabular}


$7-8$

109

*: Fulani, Akan, dago; **: artisan, hairdressing, farming, buying, and selling.

\section{Multivariable logistic regression (MLR) analysis for adherence to SMC}

Table 5 shows the results of MLR, SMC adherence analysis, and selected independent variables. Data from the 388 caregivers in Builsa North District who said they received the AQ+SP in July 2020 were used to perform this logistic regression model.

Place of residence, level of satisfaction, marital status, number of children under five, occupation, SMC Level of knowledge, knowledge of SMC's purpose, source of knowledge on SMC, household size was used to perform a simple and logistic regression.

The place of residence, the level of satisfaction, knowing SMC through a friend, residing in a household of at least five other persons, affected the SMC adherence.

The odd of adherence is 2.62 times higher among caregivers residing in urban areas than caregivers residing in rural areas. This finding was not found to be significant while unadjusted, but it was found to be statistically significant when adjusting for other factors (Adjusted $\mathrm{OR}=2.62,95 \% \mathrm{CI}=[0.96,7.14]$ ).

Participants who reported being very dissatisfied with drug distributors had $98 \%$ lower adherence odds than those who reported being very satisfied (Crude $\mathrm{OR}=0.02 ; 95 \% \mathrm{CI}=[0.00-0.27]$ ).

Respondents reporting their knowledge source as a friend had $93 \%$ lower odds of adherence than those reporting their knowledge source as health centers (Crude $\mathrm{OR}=0.07,95 \% \mathrm{CI}=[0.01-0.41])$. Respondents who indicated that their household composition is six or more is 3.24 times more likely to adhere than those who indicated that their household size is less than six (Crude OR=3.24, 95\% CI $=[1.04-10.04])$. 
Table 5: Factors associated with adherence to SMC for logistic regression.

\begin{tabular}{|c|c|c|c|c|c|c|}
\hline \multirow[b]{2}{*}{ Characteristics } & \multicolumn{2}{|c|}{ Observations } & \multicolumn{2}{|c|}{ Crude Odd Ratio } & \multicolumn{2}{|c|}{ Adjusted Odd Ratio } \\
\hline & Non-Adherent & Adherent & OR (95\% CI) & p-value & OR $(95 \% \mathrm{CI})$ & p-value \\
\hline \multicolumn{7}{|l|}{ Place of residence } \\
\hline Rural (Ref.) & 12 & 160 & 1 & & 1 & \\
\hline $\begin{array}{l}\text { Urban } \\
\text { Satisfaction Level }\end{array}$ & 6 & 210 & $2.62(0.96-7.14)$ & 0.059 & $3.59(1.02-12.56)$ & $0.045 * *$ \\
\hline Very satisfied (Ref.) & 2 & 81 & 1 & & 1 & \\
\hline Satisfied & 8 & 264 & $0.81(0.17-3.91)$ & 0.798 & $0.74(0.13-4.10)$ & 0.735 \\
\hline Dissatisfied & 6 & 23 & $0.09(0.01-0.50)$ & $0.006 * *$ & $0.10(0.01-0.74)$ & $0.024 * *$ \\
\hline $\begin{array}{l}\text { Very dissatisfied } \\
\text { Marital Status }\end{array}$ & 2 & 2 & $0.02(0.00-0.27)$ & $0.003 * *$ & $0.02(0.00-0.37)$ & $0.008 * *$ \\
\hline Single (Ref.) & 6 & 66 & 1 & & 1 & \\
\hline Married & 9 & 229 & $2.31(0.79-6.73)$ & 0.124 & $3.68(0.93-14.60)$ & 0.063 \\
\hline Cohabiting & 2 & 48 & $2.18(0.42-11.28)$ & 0.352 & $4.45(0.49-40.03)$ & 0.183 \\
\hline $\begin{array}{l}\text { Divorced /Widowed } \\
\text { Number of Children Under-five }\end{array}$ & 1 & 27 & $2.45(0.28-21.36)$ & 0.416 & $1.67(0.15-18.35)$ & 0.673 \\
\hline One child (Ref.) & 10 & 232 & 1 & & 1 & \\
\hline $\begin{array}{l}\text { Two and more child } 5 \text { under five } \\
\text { Occupation }\end{array}$ & 8 & 138 & $0.36(0.28-1.92)$ & 0.542 & $0.51(0.15-1.69)$ & 0.272 \\
\hline Unemployed (Ref.) & 10 & 176 & 1 & & 1 & \\
\hline Formal work & 4 & 109 & $1.54(0.47-5.06)$ & 0.469 & $2.7(0.55-13.05)$ & 0.216 \\
\hline $\begin{array}{l}\text { Others } \\
\text { SMC Knowledge Level }\end{array}$ & 4 & 85 & $1.20(0.36-3.96)$ & 0.756 & $1.57(0.36-6.84)$ & 0.546 \\
\hline Low knowledge (Ref.) & 17 & 320 & 1 & & 1 & \\
\hline $\begin{array}{l}\text { Good knowledge } \\
\text { Knowing the purpose }\end{array}$ & 1 & 50 & $2.65(0.34-20.40)$ & 0.348 & $1.93(0.18-20.03)$ & 0.582 \\
\hline No (Ref.) & 4 & 53 & 1 & & & \\
\hline Yes & 14 & 317 & $1.70(0.54-5.38)$ & 0.361 & $1.03(0.20-5.31)$ & 0.966 \\
\hline
\end{tabular}




\section{Source of knowledge on SMC}

Health Centers (Ref.)

Community Leaders

4

Public annoucement

Friends

Radio

TV

0

$0.86(0.09-8.12)$

$0.37(0.06-2.20)$

$0.07(0.01-0.41)$

$0.88(0.25-3.11)$

6

$0.88(0.25-3.11)$

165

$0.15(0.01-1.67)$

232

1

$<$ six people (Ref.)

10

$8 \quad 138$

$3.24(1.04-10.04)$

$\begin{array}{ccc}0.901 & 0.43(0.03-5.56) & 0.519 \\ 0.279 & 0.30(0.02-3.30) & 0.327 \\ 0.003 * * & 0.04(0.00-0.51) & 0.013 * * \\ 0.855 & 0.36(0.08-1.62) & 0.187 \\ 0.124 & 0.72(0.02-19.33) & 0.85\end{array}$

Six people and more

$0.041^{* *}$

$8.26(1.81-37.62)$

$0.006^{* *}$

**: p-value $<0.05 ;$ For all observations less than 5 , the p-value used was Fischer exact 


\section{Discussion}

This study has identified some factors that significantly influenced the adherence to unsupervised daily doses of SMC among caregivers in Builsa North District during the first SMC campaign in 2020.

The study shows that the adherence rate to the SMC equal to $95.36 \%$. This study also provides further evidence that having more than one child under five, inquiring information on SMC through any other sources deafferents from health professionals and being dissatisfied with the SMC are associated with a decrease of the odds of adherence to SMC.

In this study, the caregivers who adhered to SMC represented 95.36\% Diawara et al. reported that self-reported adherence to SMC is similar to $95 \%$, but the reliability in this regard is uncertain [6]. While this was not in SMC's setting, a study comparing various malaria preventive regimens in Ugandan children showed that adherence to a 3 -day course of dihydroartemisinin-piperaquine was much higher when reported by the caregiver $(\sim 100 \%)$ compared to the unbiased concentration of drugs [7]. A lower adherence was found using a longitudinal study in Nigeria by Ward et al. Their research found that the adherence was $83.8 \%$ [8]. Several factors may explain these observations, and a mix of these reasons rather than one alone is likely responsible. First, there may have been a good understanding of SMC in the Ghanaian community than Nigerian because the Ghanaian health system is better in terms of coverage than Nigerian's [9]. It is possible that the SP-AQ intervention improvements over the years contributed to increasing the adherence in Builsa North District by reducing the frequency and/or severity of infections among participating children. A similar study in southern Ghana and other African countries using AS+AQ also found a high adherence level $(81 \%$ - 97\%) among caregivers [10]. These findings indicate that high adherence to AS+AQ can be reached in remote areas where a successful treatment education program is in place. However, the adherence rate found in this sample could be an overestimation.

A randomized, placebo-controlled SMC trial in Ghana showed nearly 100\% self-reported adherence to SMC's 3day course across all research communities. However, some caregivers were found to have residual SMC tablets that had not been administered [11]. Another way to measure the adherence is by testing the levels of medications in children's blood during a follow-up period [11].

To reduce malaria incidence in children under five within an endemic community, a high proportion of adherence to SMC is indispensable. The adherence demonstrated by this study is associated with mainly to the good knowledge of SMC, the knowledge of SMC's purpose, the larger household size, the place of residence, the satisfaction of caregivers with previous SMC, the source of knowledge of caregivers about SMC.

The study revealed that the respondents demonstrated a better awareness of malaria and SMC. This result is not different from what Mazigo et al. and Ingabire et al. reported on the knowledge of SMC [12]. Having good knowledge is a basic predisposition for committing to adhere to all three doses of AQ-SP.

There is a tremendous need to intervene in the communication channels related to the SMC. The caregivers who reported that there had been introduced to SMC through their friend are likely to not adhere to the 3-day protocol. In contrast, those introduced through professional sources are likely to adhere. This factor may be explained by a lot of rumors that go from one to another about all the mass drug administration (MDA). Some people do not trust any free medication. In some remote areas, people still trusting only traditional medicine. This knowledge gap may explain the lack of importance of those who reported they forgot to give medicine to children.

There was a difference in household size observed in this study. Households composed of more than 5 people are more likely to adhere to SMC; this may be due to the increased number of people (sisters, brothers) to take care of children, the primary caregivers.

The perceptive factor assessed in this study is the satisfaction level with SMC. The majority of caregivers reported that they are satisfied with SMC.

However, the study found that the tendency to adherence varied significantly with caregivers' level of satisfaction, the more they are satisfied more they adhered to SMC. In Mali Diawara et al. found that parents' opinions about SMC were very positive, with $99.9 \%$ of parents reporting that they felt the strategy was good or very good, and $99 \%$ of them were in favor of continuing the intervention. SMC's strong support and favorable opinion are major assets for continuation and scale-up [13]

The reasons for non-adherence in this study were the child's refusal to swallow the drug, vomiting, illness after the first dose, and the mother's forgetting about the medication. In Niger, Ding et al., 2020b found that children refusing to take the drug; suboptimal health worker instructions; small children spitting out medication, even if it is dissolved; vomiting within 30 minutes of dosing; caregiver saving medicines for the treatment of another family member with acute malaria later on; caregivers sharing/giving medication to older children who were not eligible for SMC; fathers not allowing the medicine to be taken; and fatigue of giving medication, mainly when the child is not sick were the main reason for non-adherence cited by study participants were the main reasons of nonadherence to SMC [14]

Ultimately, an integrated approach to funders, policymakers, health workers, applied health social scientists, drug distributors, community members, and all stakeholders will be appropriate for achieving the National Malaria Control Program's goal in the Upper East region of Ghana. 


\section{Limitations of the study}

Study results were based on the opinions and experiences of a representative Builsa North District subdistricts, not for all the Upper East Region of Ghana. Therefore, the results can be generalized only to the sampled population in the district and not to the whole regional or national level.

The present study adopted a quantitative approach only. A mixed approach (both quantitative and qualitative) would help define the deep reasons behind the non-adherence influencing factors.

\section{Strength of the study}

The strengths of this study include the fact that the study was carried out by a research team that was not involved in the implementation of the SMC.

There is a possibility for selection and observer bias as with any observational study. Study participants were selected at random to eliminate these biases.

The potential of recall bias could not be omitted; to minimize them, the survey was conducted in the four subdistricts about one week after the first round of SMC 2020.

\section{Conclusion}

The present study found the level of SMC adherence in Builsa North District, Upper East Ghana.

The main reason for non-adherence is the child's refusal to take the drug, the child vomiting, the occurrence of a disease, the caregiver's forgetting about medication.

Caregivers with good knowledge, those who have obtained extensive information about SMC from health care providers, those who have only one child, those who live in Town are likely to adhere to SMC.

The results of this study indicate that the caregivers in the district of Builsa North have a very good knowledge of the cause of malaria, its consequences on children, and its preventive methods. It also shows that more than half of caregivers in the district are aware of Seasonal Malaria Chemoprevention.

There has been considerable progress in Ghana's implementation of SMC at the district level. However, some factors regarding SMC, like child refusal to take medicine, still have a bad effect on adherence rate to unsupervised doses. If specific strategies are not implemented to control them, they could spread and undermine all attempts made so far to achieve the reduction of the burden of malaria in children under five may be spread.

\section{List of Abbreviations}

$\begin{array}{ll}\text { AQ }- \text { SP } & \text { Amodiaquine }+ \text { Sulfadoxine-Pyrimethamin } \\ \text { CHPS } & \text { Community-Based Health Planning and Services } \\ \text { CHWs } & \text { Community Health Workers } \\ \text { GHS } & \text { Ghana Health Services } \\ \text { MLR } & \text { Multivariable Logistics Regressions } \\ \text { RA } & \text { Research Assistants } \\ \text { SMC } & \text { Seasonal Malaria Chemoprevention } \\ \text { UER } & \text { Upper East Region } \\ \text { UWR } & \text { Upper West Region } \\ \text { WHO } & \text { World Health Organization }\end{array}$

\section{Declaration:}

\section{Ethical Consideration}

Ethical approval for the protocol of this survey was obtained from Ghana Health Service Ethical Committee [GHS-ERC 034/02/20]. In August 2020, community meetings were held with caregivers and local community representatives to explain the study's purpose, after which communities were offered the choice to participate in the survey. Signed consent before the interview was also obtained from all the caregivers interviewed during the study.

The study had been carried out during the COVID-19 pandemic, so participating in this study presented a minimal risk of COVID-19 transmission. To ensure the study participants' and research assistants' protection, the study adopted safety measures such as PPEs (Personal Preventive Equipment) by study participants and the interviewers. The study ensured that the interviews maintain a social distance of at least 6 feet (about two arm lengths).

\section{Funding information:}

This study is aligned to a master's degree in Public Health funded by the World Health Organization-Special Program on Tropical Disease Research (WHO/TDR) through the African Regional Training Center (ARTC) and Office of Research Innovation and Development (ORID) at the University of Ghana.

Competing interests: No competing interests

Authors' contribution

Conceptualization: Cheick Oumar Doumbia, Ernest Kenu

Data curation: Cheick Oumar Doumbia.

Formal analysis: Cheick Oumar Doumbia,

Methodology: Cheick Oumar Doumbia, Ernest Kenu,

Project administration: Ernest Kenu, Cheick Oumar Doumbia 
Supervision : Ernest Kenu, Seydou Doumbia, Mahamadou Diakite.

Validation : Ernest Kenu, Mahamadou Diakite, Seydou Doumbia.

Writing - original draft: Cheick Oumar Doumbia.

Writing - review \& editing: Cheick Oumar Doumbia, Ernest Kenu, Samba Diarra, Mountaga Diallo, Ilo Dicko, Brahima Konate.

\section{Acknowledgments}

We would like to acknowledge the Builsa North District's district directory, which provided permission for this study to be carried out.

\section{Authors' Information}

1: University Clinical Research Center, University of Science Techniques and Technologies of Bamako

2: School of Public Health, University of Ghana

3: Malaria Research and Training Center, University of Sciences Techniques and Technologies of Bamako.

\section{Consent for Publication}

Not applicable for that section

Availability of data and materials

Not applicable for that section

\section{References}

1. WHO | World Malaria Report 2012. WHO. 2014;

2. York A. Seasonal malaria chemoprevention in the Sahel. The Lancet Infectious diseases. 2017 Jun 1;17(6):588.

3. Druetz T. Evaluation of direct and indirect effects of seasonal malaria chemoprevention in Mali. Scientific Reports. 2018 Dec 1;8(1).

4. Chatio S, Ansah NA, Awuni DA, Oduro A, Ansah PO. Community acceptability of Seasonal Malaria Chemoprevention of morbidity and mortality in young children: A qualitative study in the Upper West Region of Ghana. Dionne-Odom J, editor. PLOS ONE [Internet]. 2019 May 17 [cited 2020 Jan 6];14(5):e0216486. Available from: http://dx.plos.org/10.1371/journal.pone.0216486

5. Ghana Overview [Internet]. [cited 2020 Sep 6]. Available from: https://www.worldbank.org/en/country/ghana/overview

6. Diawara F, Steinhardt LC, Mahamar A, Traore T, Kone DT, Diawara H, et al. Measuring the impact of seasonal malaria chemoprevention as part of routine malaria control in Kita, Mali. Malaria journal [Internet]. 2017 Aug 10 [cited 2020 Sep 11];16(1):325. Available from: /pmc/articles/PMC5553795/?report=abstract

7. Bruxvoort K, Festo C, Cairns M, Kalolella A, Mayaya F, Kachur SP, et al. Measuring Patient Adherence to Malaria Treatment: A Comparison of Results from Self-Report and a Customised Electronic Monitoring Device. PLoS ONE [Internet]. 2015 Jul 27 [cited 2020 Sep 11];10(7). Available from: /pmc/articles/PMC4516331/?report=abstract

8. Ward A, Guillot A, Nepomnyashchiy LE, Graves JC, Maloney K, Omoniwa OF, et al. Seasonal malaria chemoprevention packaged with malnutrition prevention in northern Nigeria: A pragmatic trial (SMAMP study) with nested case-control. PLoS ONE. 2019 Jan 1;14(1).

9. Amu H, Dickson KS, Kumi-Kyereme A, Maafo Darteh EK. Understanding variations in health insurance coverage in Ghana, Kenya, Nigeria, and Tanzania: Evidence from demographic and health surveys. PLoS ONE [Internet]. 2018 Aug 1 [cited 2020 Oct 11];13(8). Available from: https://pubmed.ncbi.nlm.nih.gov/30080875/

10. Asante KP, Owusu R, Dosoo D, Awini E, Adjei G, Amenga Etego S, et al. Adherence to ArtesunateAmodiaquine Therapy for Uncomplicated Malaria in Rural Ghana: A Randomised Trial of Supervised versus Unsupervised Drug Administration. Journal of Tropical Medicine [Internet]. 2009 [cited 2020 Oct 11];2009:1-7. Available from: /pmc/articles/PMC2836893/?report=abstract

11. Bigira V, Kapisi J, Clark TD, Kinara S, Mwangwa F, Muhindo MK, et al. Protective efficacy and safety of three antimalarial regimens for the prevention of malaria in young Ugandan children: A randomized controlled trial. PLoS Medicine [Internet]. 2015 [cited 2020 Sep 11];11(8). Available from: /pmc/articles/PMC4122345/?report=abstract

12. Mazigo HD, Obasy E, Mauka W, Manyiri P, Zinga M, Kweka EJ, et al. Knowledge, Attitudes, and Practices about Malaria and Its Control in Rural Northwest Tanzania. Malaria Research and Treatment. 2010;2010:1-9.

13. Diawara F, Steinhardt LC, Mahamar A, Traore T, Kone DT, Diawara H, et al. Measuring the impact of seasonal malaria chemoprevention as part of routine malaria control in Kita, Mali. Malaria journal. 
2017 Aug 10;16(1):325.

14. Ding J, Coldiron ME, Assao B, Guindo O, Blessborn D, Winterberg M, et al. Adherence and Population Pharmacokinetic Properties of Amodiaquine When Used for Seasonal Malaria

Chemoprevention in African Children. Clinical Pharmacology \& Therapeutics [Internet]. 2020 May 31 [cited 2020 Sep 7];107(5):1179-88. Available from:

https://onlinelibrary.wiley.com/doi/abs/10.1002/cpt.1707. 
Figures

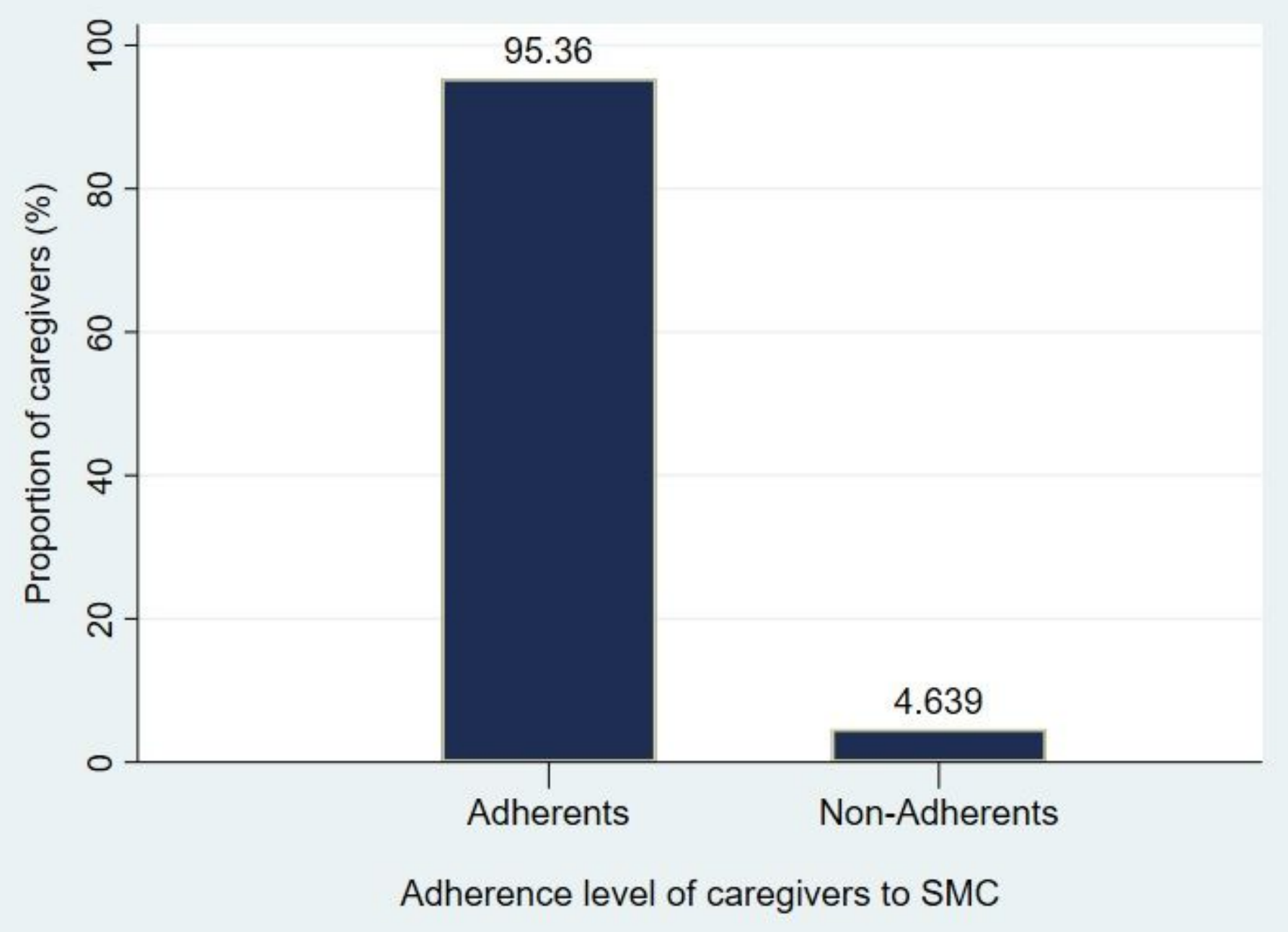

Figure 1

Adherence level of caregivers to SMC during the first in Builsa North District 2020 


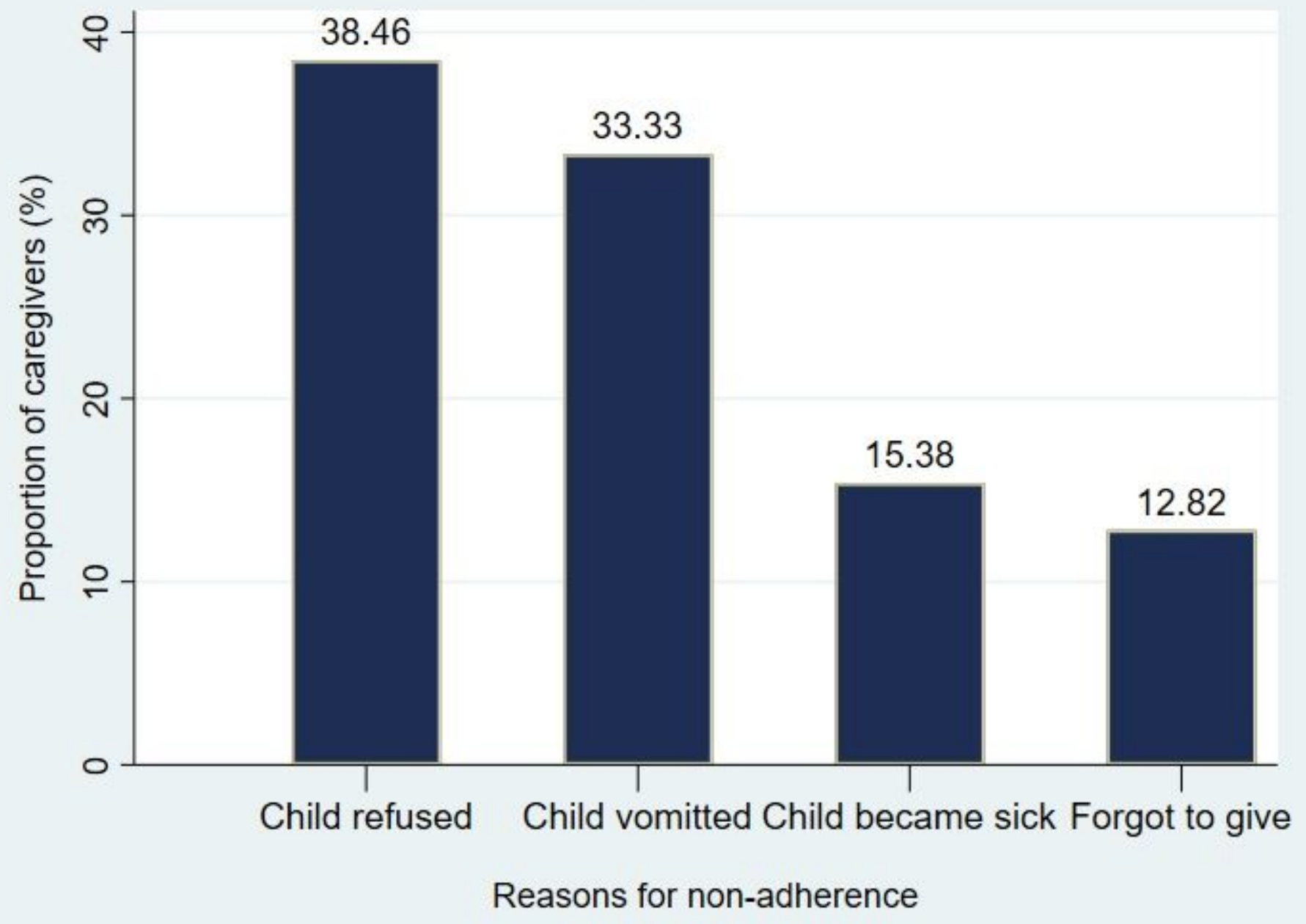

Figure 2

Reasons for non-adherence to unsupervised daily treatment doses of SMC 


\section{Proportion of awereness about SMC among caregivers}

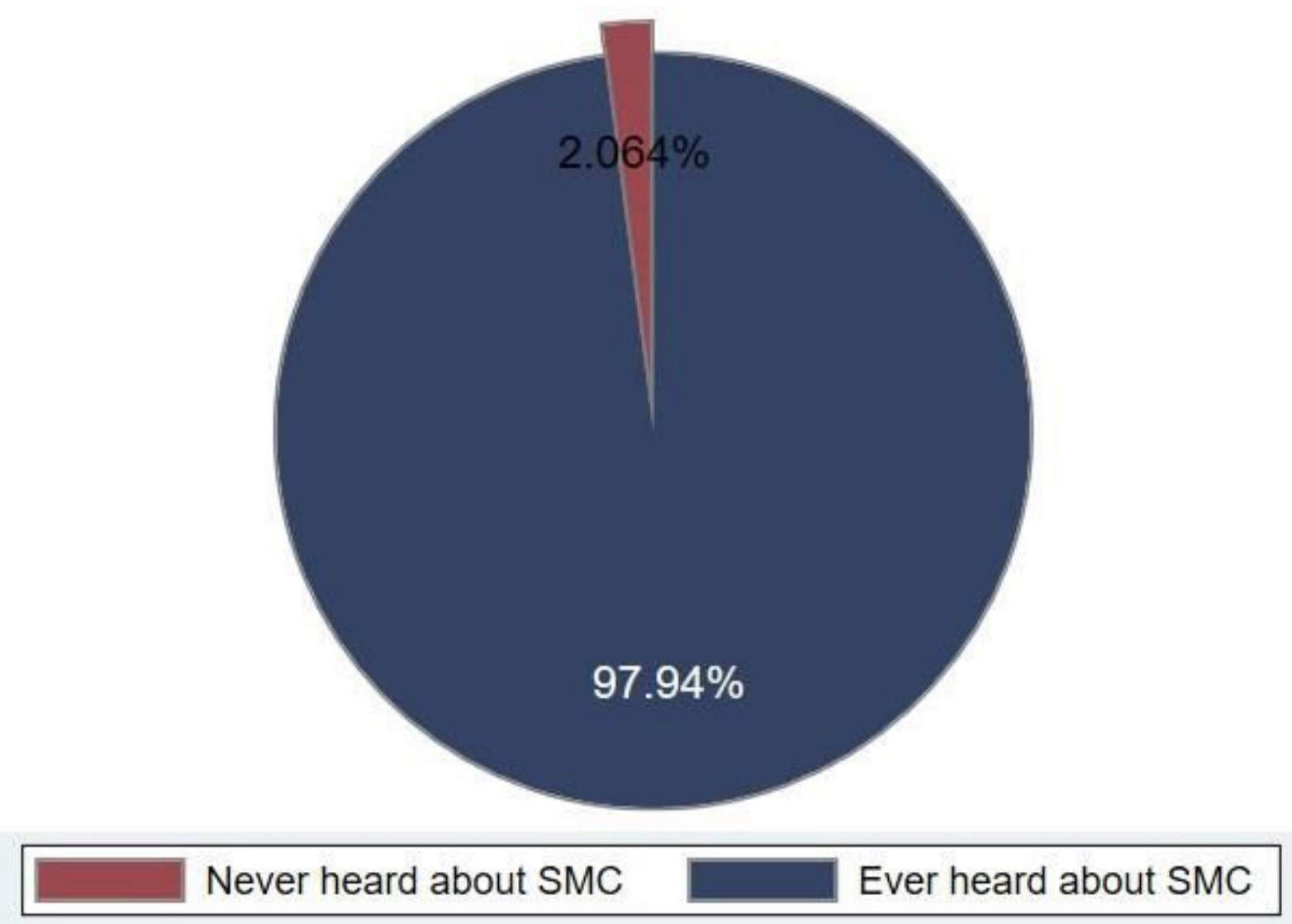

Figure 3

Levels of awareness of Seasonal Malaria Chemoprevention 


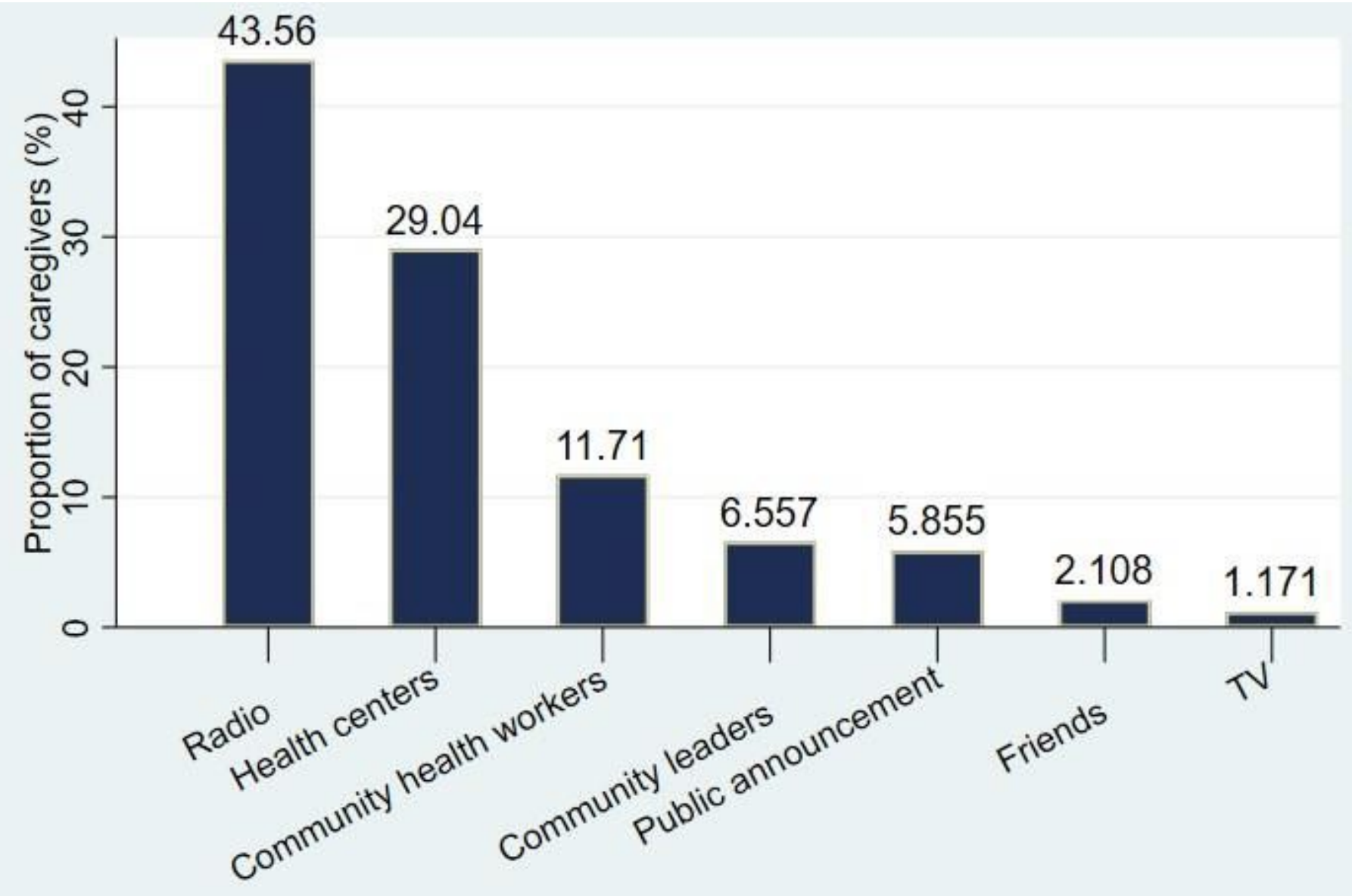

Sources of Knowledge on SMC

Figure 4

Source of Knowledge on SMC 